\title{
Epidemiological and clinical outcome comparison of indirect ('strain') versus direct ('contusion') anterior and posterior thigh muscle injuries in male elite football players: UEFA Elite League study of 2287 thigh injuries (2001-2013)
}

\author{
Peter Ueblacker, ${ }^{1,2}$ Hans-Wilhelm Müller-Wohlfahrt, ${ }^{1,2}$ Jan Ekstrand ${ }^{3,4}$
}

\begin{abstract}
${ }^{1} \mathrm{MW}$ Center of Orthopedics and Sports Medicine, Munich, Germany

${ }^{2}$ Football Club FC Bayern

Munich, Germany

${ }^{3}$ Football Research Group,

Department of Medical and

Health Sciences, Linköping

University, Linköping, Sweden

${ }^{4}$ UEFA Injury Study Group,

UEFA Medical Committee,

Nyon, Switzerland
\end{abstract}

\section{Correspondence to}

Dr Peter Ueblacker, MW Center

of Orthopedics and Sports

Medicine, Munich, Germany,

Dienerstrasse 12, Munich

80331, Germany;

peter.ueblacker@gmx.net

Accepted 25 January 2015

Published Online First

9 March 2015

\section{CrossMark}

\author{
To cite: Ueblacker $P$, \\ Müller-Wohlfahrt H-W, \\ Ekstrand J. Br J Sports Med
}

2015;49:1461-1465.

\section{ABSTRACT}

Background Data regarding direct athletic muscle injuries (caused by a direct blunt or sharp external force) compared to indirect ones (without the influence of a direct external trauma) are missing in the current literature - this distinction has clinical implications. Aim To compare incidence, duration of absence and characteristics of indirect and direct anterior (quadriceps) and posterior thigh (hamstring) muscle injuries.

Methods 30 football teams and 1981 players were followed prospectively from 2001 until 2013. The team medical staff recorded individual player exposure and time-loss injuries. Muscle injuries were defined as indirect or direct according to their injury mechanism. Results In total, 2287 thigh muscle injuries were found, representing $25 \%$ of all injuries. Two thousand and three were valid for further analysis, of which $88 \%$ were indirect and $12 \%$ direct. The incidence was eight times higher for indirect injuries $(1.48 / 1000 \mathrm{~h})$ compared to direct muscle injuries $(0.19 / 1000 h)(p<0.01)$. Indirect muscle injuries caused $19 \%$ of total absence, and direct injuries $1 \%$. The mean lay-off time for indirect injuries amounted to 18.5 days and differed significantly from direct injuries which accounted for 7 days $(p<0.001)$. $60 \%$ of indirect injuries and $76 \%$ of direct injuries occurred in match situations. Foul play was involved in $7 \%$ of all thigh muscle injuries, as well as in $2 \%$ of indirect injuries and $42 \%$ of direct injuries.

Summary Muscle anterior and posterior thigh injuries in elite football are more frequent than have been previously described. Direct injuries causing time loss are less frequent than indirect ones, and players can usually return to full activity in under half the average time for an indirect injury. Foul play is involved in $7.5 \%$ of all thigh muscle injuries.

\section{INTRODUCTION}

If one considers an injury mechanism, muscle injuries can be differentiated into indirect and direct types. $^{1} \quad 2$ Indirect muscle injuries are caused without the influence of a direct external trauma. They are either functional (non-structural) disorders without evidence of a tear, or structural injuries caused by a longitudinal distraction that tears the muscle tissue. ${ }^{1}$ Direct muscle injuries are caused by a direct blunt (contusion) or sharp (laceration) external force. In most of the direct cases, the injury mechanism is a compressive force to the thigh (such as a direct blow from an opponent's knee) that usually compresses the muscle tissue. In contrast to indirect injuries, muscle fibres are not torn by longitudinal distraction.

While indirect muscle injuries are well described, ${ }^{3-7}$ information regarding direct muscle injuries is very limited. There is no study in the literature so far that compares indirect and direct muscle injuries.

Ekstrand et $a l^{5}$ reported that indirect injuries constitute $31 \%$ of all soccer injuries, causing $27 \%$ of the total injury absence. A men's elite level team can expect 15 muscle injuries each season, and the most common single injury type is a hamstring injury. ${ }^{5}$ Ninety-six per cent of muscle injuries occur in non-contact situations, and only $2 \%$ are due to foul play. ${ }^{5}$ Direct muscle injuries were monitored in that particular study as contusions in general without specific analysis regarding location, epidemiology and nature. Thus, valid epidemiological data for elite football players are missing. However, if we look at the total muscle injury group, direct injuries such as contusions affecting muscles should also be included in the analysis and be compared with indirect injuries.

Direct injuries, especially contusions, are common in sports, especially in team sports with contact situations like football, basketball, American football, rugby and others. ${ }^{8} 9$ These injuries are usually painful and may cause considerable functional disability in the affected area. However, athletes, even those with more severe contusions, can often continue playing for some time. In many cases, players become fully aware of the injury only after leaving the field or later, when the bleeding and swelling has reached a certain level. ${ }^{9}$ In contrast, a small indirect structural injury, such as a partial tear of the muscle tissue, usually forces the player to stop at once. It has been stated that early return to full function and rehabilitative therapy after direct injuries can usually be more aggressive to the limit of pain tolerance, ${ }^{10}$ which is not the case in indirect muscle injuries. Even though these observations have great practical consequences for the medical teams, this issue has been little researched.

We aimed to investigate the incidence and characteristics of direct injuries and compare them with indirect muscle injuries in a homogeneous group of male elite football players. Our hypothesis was that time-loss direct muscle injuries would be less frequent and lead to a shorter absence compared to indirect injuries. 


\section{MATERIALS AND METHODS \\ Study population}

This study is a substudy of the general prospective injury surveillance of male elite football that started in 2001, the UEFA Champions League (UCL) Injury study (now known as the UEFA Elite Club Injury Study) which is well described in the literature. $^{25}$

In total, 1981 players from 30 European elite teams and 10 different countries were followed from July 2001 until May 2013. All contracted players in the first team were invited to participate in the study.

\section{Study design and definitions}

The full methodology and the validation of the UCL injury study design are reported elsewhere. ${ }^{11}$ The study design followed the consensus on definitions and data collection procedures in studies of football injuries. ${ }^{5} 1112$ A recordable injury was defined as "any physical complaint resulting from football activity and leading to a player being unable to fully participate in future training or matches (ie, time loss injury)."

According to the recently described Munich muscle injury classification system, muscle injuries were categorised into indirect and direct types. ${ }^{1}$ A direct muscle injury was defined as "a traumatic injury caused by a direct external trauma," an indirect injury as "a muscle injury caused without the influence of a

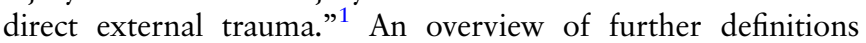
used in this study is demonstrated in table 1 .

\section{Data collection}

Player baseline data were collected at the start of the season. Individual player exposure in training and matches was registered by the clubs on a standard exposure form and sent to the study group on a monthly basis. Team medical staff recorded thigh muscle injuries on a standard injury form that was sent to the study group each month. The thigh injury form is an A4 page consisting of ticking boxes for type, location and mechanism of injury as well as diagnostic procedures and treatments. The player was considered injured until the team medical staff allowed full participation in training and availability for match selection. All injuries were followed until the final day of rehabilitation. All reports were checked each month by the study group and feedback was sent to the teams in order to correct any missing or unclear data.

\section{Statistical analyses}

Pearson's $\chi^{2}$ test was used to analyse the association between type of thigh muscle injury (direct and indirect) and various categorical variables. Absence days are presented with mean $\pm S D$ and corresponding median (Md) and IQR. Owing to the skewed distribution in absence days, group differences were analysed using the Mann-Whitney $U$ test. Injury rates (IRs) are reported as the number of injuries per 1000 player-hours and injury burden was calculated as the number of absence days per 1000 player-hours. Rate ratio (RR) with 95\% CI was used for group comparisons of injury rates and injury burden, and significance tested using $\mathrm{z}$-statistics. All tests were two sided and the significance level was set at $\mathrm{p}<0.05$. Analyses were completed using IBM SPSS Statistics V.21.0 (IBM Corp, Armonk, New York, USA).

\section{RESULTS}

\section{Basic data, exposure, injury types and incidence}

There were, on average, $28 \pm 5$ players included per team. In total, 2287 thigh muscle injuries were recorded during 5013 player seasons. Overall, $1194510 \mathrm{~h}$ of exposure (1 003270 of training and 191240 of match play) were registered.

The 2287 thigh muscle injuries amounted to $25 \%$ of all 8993 injuries. Two hundred and eighty-four (12\%) of all muscle injuries were not definable as direct or indirect ones, since data from club medical teams were missing or unclear.

The 2003 thigh muscle injuries which could be clearly categorised as indirect or direct mechanism are included in the following results: 1772 (88\%) were indirect injuries and 231 $(12 \%)$ were direct, all of them contusion injuries. Indirect muscle injuries represented $20 \%$ and direct ones $3 \%$ of all injuries.

The incidence of indirect injuries was eight times higher compared to direct injuries $(1.48 / 1000$ vs $0.19 / 1000 \mathrm{~h}, \mathrm{p}<0.001)$. An overview of basic data, incidence, absence and the associated injury burden of indirect versus direct thigh muscle injuries is seen in table 2 .

\section{Circumstances of injury}

Sixty per cent of indirect injuries and $76 \%$ of direct injuries occurred during matches, whereas $40 \%$ and 24\%, respectively, were recorded during training. Direct injuries tended to occur more frequently during the second half of matches $(57 \%$ vs $43 \%$ in the first half) compared to a more balanced distribution

Table 1 Operational definitions

\begin{tabular}{|c|c|}
\hline Injury & $\begin{array}{l}\text { Injury resulting from playing football and leading to a player being unable to fully participate in future training and match play } \\
\text { (ie, time-loss injury) }\end{array}$ \\
\hline Muscle injury & Indirect or direct injury to the muscle leading to a player being unable to fully participate in training or match play \\
\hline Return to play & Full participation in training and availability for match selection \\
\hline Indirect muscle injury & A muscle injury caused without the influence of a direct external trauma \\
\hline Functional muscle injury & Painful muscle injury/disorder (acute or chronic) without macroscopic evidence of muscle fibre damage (seen in ultrasound/MRI) \\
\hline Structural muscle injury & Any acute indirect muscle injury with macroscopic evidence of muscle fibre damage (seen in ultrasound/MRI) \\
\hline Direct muscle injury & A traumatic muscle injury caused by a direct (blunt or sharp) external trauma \\
\hline Contusion & Tissue bruise without concomitant injuries classified elsewhere \\
\hline Muscle contusion & Direct muscle trauma, caused by blunt external force \\
\hline Laceration & Direct trauma including skin and subcutaneous tissue, caused by sharp external force \\
\hline Foul play & Violation of the laws of the game according to the match referee \\
\hline Lay-off/absence & Number of days until the player resumed full team training \\
\hline Re-injury/recurrency & $\begin{array}{l}\text { Injury of the same type and at the same site as an index injury occurring no more than } 2 \text { months after a player's return to full participation } \\
\text { from the index injury }\end{array}$ \\
\hline
\end{tabular}


Table 2 Basic data, incidence, absence and injury burden of indirect versus direct thigh muscle injuries

\begin{tabular}{|c|c|c|c|}
\hline & Total & Indirect thigh muscle injuries & Direct thigh muscle injuries \\
\hline Number of thigh muscle injuries (\% of total number of injuries) & $2287(25.4)$ & & \\
\hline $\begin{array}{l}\text { Number of thigh muscle injuries included in this analysis } \\
\text { (\% of total number of injuries) }\end{array}$ & $2003(22.3)$ & $1772(19.7)$ & $231(2.6)$ \\
\hline Percentage of total number of thigh muscle injuries & 100 & 88.5 & 11.5 \\
\hline \multicolumn{4}{|l|}{ Injury incidence* } \\
\hline Total & 1.67 (1.61 to 1.75$)$ & 1.48 (1.42 to 1.55$)$ & 0.19 (0.17 to 0.22$)$ \\
\hline Training & $0.76(0.71$ to 0.82$)$ & $0.71(0.66$ to 0.76$)$ & $0.06(0.04$ to 0.07$)$ \\
\hline Match & 6.47 (6.12 to 6.84$)$ & $5.56(5.23$ to 5.90$)$ & $0.92(0.79$ to 1.06$)$ \\
\hline \multicolumn{4}{|l|}{ Days of absence/injury } \\
\hline Mean \pm SD & $17.2 \pm 18.9$ & $18.5 \pm 19.5$ & $7.0 \pm 9.1$ \\
\hline Median (IQR) & $12(15)$ & $13(16)$ & $4(5)$ \\
\hline Range & $0-247$ & $1-247$ & $0-93$ \\
\hline Absence (\% of total injury absence) & 19.6 & 18.7 & 0.9 \\
\hline Injury burdent & 28.8 (28.5 to 29.1$)$ & 27.5 (27.2 to 27.8$)$ & 1.4 (1.3 to 1.4$)$ \\
\hline Re-injuries (\%) & $226(11.3)$ & $225(12.7)$ & $1(0.4)$ \\
\hline
\end{tabular}

*Incidence of thigh muscle injuries expressed as number of injuries $/ 1000 \mathrm{~h}$ of total exposure $(95 \% \mathrm{Cl})$.

tInjury burden expressed as number of days' absence/1000 h of total exposure (incidencexmean absence) $(95 \% \mathrm{Cl})$.

across the full course of the match for indirect injuries $(49 \%$ in the second half vs $51 \%$ in the first half) (in both injury types without significant association, $\mathrm{p}=0.137)$. In both groups, there was a tendency for more injuries to occur towards the end of the two halves. The distribution of both injury groups by match period of $15 \mathrm{~min}$ is shown in figure 1 .

Naturally, and as defined, all direct injuries occurred in contact situations, the vast majority involving other players; in one case, a direct injury was sustained after contact with an object. In contrast, $96 \%$ of the indirect injuries occurred in non-contact situations. The majority, that is, $60 \%$ of all indirect injuries, occurred during sprinting or high-speed running, 14\% resulted from shooting and $3 \%$ in stretching situations.

Foul play was involved in a total of $7 \%$ of all muscle injuries. A distinct difference was observed between the two injury groups: $2 \%$ of indirect injuries compared to $42 \%$ (56\% collision, $23 \%$ kicked, $10 \%$ tackled) of direct injuries resulted from fouls.

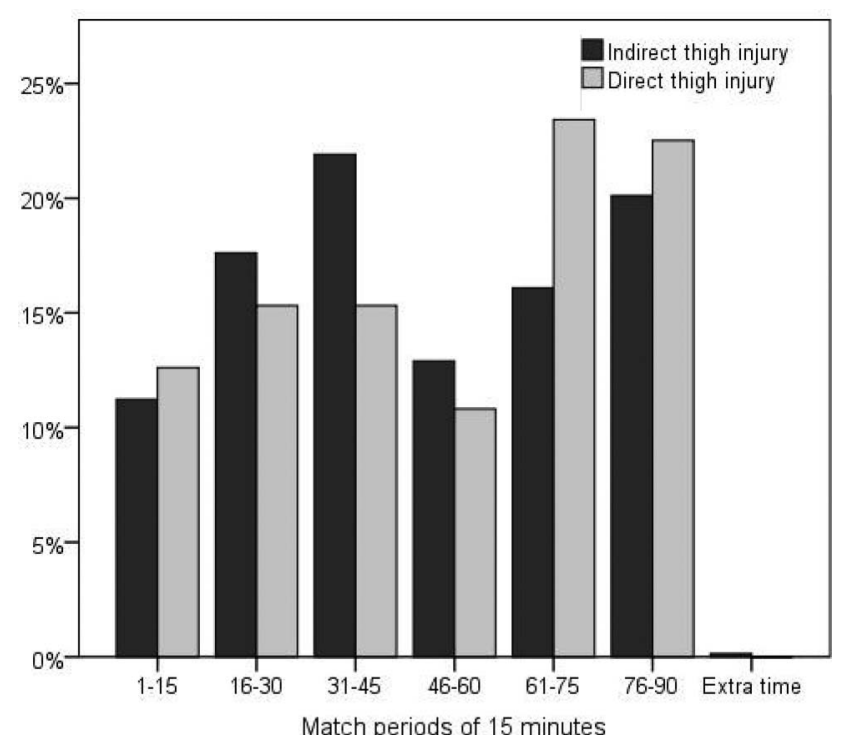

Figure 1 Distribution of indirect and direct thigh muscle injuries by match period of $15 \mathrm{~min}$.

\section{Absence after indirect and direct muscle injury and re-injuries}

As seen in table 2, the mean absence of all thigh muscle injuries was 17.2 \pm 18.9 (median 12) days. Mean absence after indirect injury amounted to $18.5 \pm 19.5$ (median 13) days compared to $7.0 \pm 9.1$ (median 4) days for direct injuries $(\mathrm{p}<0.001)$ (figure 2).

The absence in relation to all injuries (total injury absence) was $19.6 \%$ for all injuries, $18.7 \%$ for indirect injuries and $0.9 \%$ for direct muscle injuries, that is, 20.2 times higher for indirect injuries compared to direct injuries.

The injury burden, expressed as the number of days absence/ $1000 \mathrm{~h}$ of total exposure (incidence $\times$ mean absence), accounted for 27.5 of indirect injuries and 1.4 of direct muscle injuries $(\mathrm{p}<0.001)$.

The re-injury rate for all injuries in the study was $11 \%$. The recurrence rate of indirect muscle injuries was $13 \%$ compared to only $0.4 \%$ for direct muscle injuries.

\section{DISCUSSION}

Muscle injuries of the thigh are even more frequent in elite football than were previously considered and published. In previous

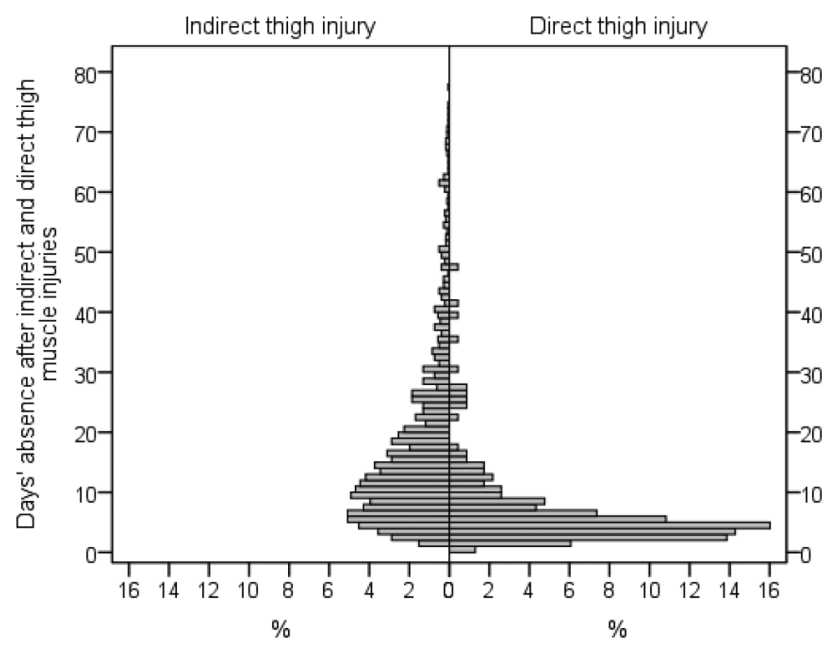

Figure 2 Days of absence after indirect and direct thigh muscle injuries. 
studies, these injuries accounted for $17 \%$ of all injuries. ${ }^{5}$ However, this number only represented injuries that had been indirect. Contusions and other direct muscle injuries were not monitored as muscle injuries. ${ }^{5}$

\section{Direct injuries account for $12 \%$ of time-loss thigh muscle injuries}

Direct injuries represent almost 3\% of all muscle injuries and $12 \%$ of time-loss thigh muscle injuries in elite football causing approximately $1 \%$ of total injury absence. In contrast, indirect thigh muscle injuries represent almost $20 \%$ of all injuries, whereas $88 \%$ of time-loss thigh injuries cause almost $19 \%$ of the total injury absence.

\section{Shorter absence after muscle contusion compared to indirect muscle injury}

Jackson and Feagin ${ }^{13}$ reported that the average return to sport without proper treatment of thigh contusion was 45 days. On the basis of the present study, the mean absence after direct muscle injuries was 7 days with a median (which is probably the more useful value regarding expected absence) of 4 days. Mean absence after indirect injury was significantly longer and 18.5 days. Total absence for all muscle injuries amounted to 16.2 days, which is comparable to previous studies. ${ }^{5}$ Compared to the data of Jackson and Feagin, our study possibly indicates that top-level clubs in Europe have effective medical support, providing individualised rehabilitation for players after muscle contusion. However, the high SD as well as the high range shows that there are a range of muscle injury grades within both groups. These injuries could not be further subdifferentiated in our study since a more detailed classification system, the Munich consensus classification, was not implemented in the UCL study until 2013. ${ }^{12}$

Total injury absence was 20.2 times higher and injury burden 19.6 times higher for indirect injuries compared to direct. As mentioned earlier, contusion injuries cause pain and loss of motion. However, muscle fibres are usually compressed, but not torn by longitudinal distraction. ${ }^{1}$ Thus, rehabilitative therapy can usually be more aggressive, up to the limit of pain tolerance. Function is progressively increased as motion and strength return. ${ }^{10}$ One might speculate that this explains the shorter absence and lower injury burden of direct injuries.

Healing of muscle tears is a gradual process, and time is needed to restore the strength of the muscle to the pre-injury level. ${ }^{15}$ Thus, returning to full activity without a total healing of the muscle tissue and without a total recovery of tensile strength is likely to lead to a more severe re-injury. ${ }^{1}{ }^{14}$ The greatest risk is during the initial 2 weeks following return to sport. ${ }^{15}$

In this study, the recurrence rate of indirect thigh muscle injuries was $13 \%$, confirming previous studies. ${ }^{5} 6$ The re-injury rate of direct injuries amounted to only $0.4 \%$. However, varying degrees of direct muscle injury can occur-some direct injuries in this study caused long absences (see table 2). Another reason for the low re-injury rate might be that team physicians probably report a problem after muscle contusion as a different diagnosis and not as a re-injury.

\section{Many direct injuries during matches}

It is well known that muscle injuries occur more frequently during matches than during training. ${ }^{5}$ However, data were so far only available for indirect injuries. In our study, we found that direct injuries occur even more frequently during matches: $76 \%$ of direct injuries compared to $60 \%$ of indirect injuries. Direct injuries tended to occur more frequently during the second half of matches and there was a tendency for more injuries to occur towards the end of each half. Our findings suggest that teams play more aggressively during matches compared to training as well as towards the end of matches. This extends previous findings that $90 \%$ of footballers are ready to commit an intentional foul if required, depending on the score and importance of the match. ${ }^{16}$

\section{More than $\mathbf{4 0} \%$ of thigh muscle contusions due to foul play}

Around $20 \%$ of match injuries are due to fouls. ${ }^{17}$ Thus, foul play is one of the most important known extrinsic risk factors for injuries in football. ${ }^{18}$ It is well documented that injuries caused by foul play are mostly sprains or contusions affecting the lower extremity. ${ }^{17-20}$

Our data indicate that $7.5 \%$ of all thigh muscle injuries were related to foul play. A distinct difference was observed between the two injury groups: $1.7 \%$ of indirect injuries compared to $42 \%$ of direct injuries resulted from fouls. This suggests that stricter refereeing could reduce the risk of direct injuries.

\section{Medical history is the key to differentiate direct injuries from indirect injuries}

Diagnosis of muscle injuries can be complex. It should be based primarily on clinical findings, with imaging providing additional information to confirm the diagnosis. ${ }^{46721}$ Medical history is crucial, and the simple question 'was there a kick or collision' to the player has a direct practical relevance. It has been described that rehabilitation can be more aggressive to the limit of pain tolerance after muscle contusion, ${ }^{10}$ which is not the case for indirect muscle injuries. ${ }^{1}$

MRI has been the preferred imaging for muscle injuries in recent years. ${ }^{22-25}$ However, when it is used in isolation, it can lead to misinterpretation since there are no specific pathological changes separating direct from indirect injuries. ${ }^{26}$ Moreover, the resolution of the injury as detected by MRI can lag behind functional recovery, in indirect injuries, ${ }^{27} 28$ as well as in direct injuries. ${ }^{10}$ A haematoma or oedema can still be apparent on MRI taken weeks and even months after return to play. ${ }^{10} 2728$ Diaz et $a l^{10}$ showed that, despite markedly abnormal imaging studies, athletes were able to compete at the highest professional level without functional loss after a muscle contusion.

\section{Methodological considerations}

An obvious strength of this study is its design, with a homogeneous group of male elite footballers followed prospectively with a standardised methodology. ${ }^{11}{ }^{12}$ Another strength is the number of players included; for the first time, all thigh muscle injuries (ie, hamstring and quadriceps) were analysed, which makes the numbers substantially larger than in previous studies.

A limitation of the study is the absence of subdifferentiation of muscle injuries. Thus, the material includes muscle injuries of different severities and of different sizes. A more detailed classification, for example the Munich consensus classification system, would have been useful. Unfortunately, $12 \%$ of all muscle injuries were not definable as direct or indirect ones, since data from club medical teams were missing or unclear. Furthermore, our study population was limited to male elite football players and might therefore not necessarily reflect the injury characteristics of a more general population or other levels of play. Regarding data collection, potential limitations included the risk for observer bias from the lack of an independent injury classification and evaluation for return to play performed by the same team medical staff. 
Although our data and considerations represent a high number of muscle injuries, as well as a long clinical experience, more specific data would be useful in order to develop an algorithm for the management of muscle injuries that integrates clinical and imaging information.

On the basis of our data, we propose an updated (new) definition of muscle injury as "an indirect or direct injury to the muscle leading to an athlete being unable to fully participate in training or match play/competition."

\section{SUMMARY}

Muscle injuries in elite football are more frequent than have been previously described. Foul play is involved in $7.5 \%$ of all thigh muscle injuries. Medical history is essential to differentiate direct injuries from indirect injuries. Time-loss direct injuries are less frequent than indirect injuries. These direct injuries are associated with a more rapid return to full function as rehabilitative therapy can usually be more aggressive to the limit of pain tolerance. Thus, direct injuries have a shorter absence time compared to indirect injuries.

\section{What are the new findings?}

This very large study characterises direct muscle injuries and compares them with indirect injuries. Overall, thigh muscle injuries (ie, anterior and posterior) are more frequent than have been previously described; about $20 \%$ of all time-loss injuries were of the indirect type and 3\% of all time-loss injuries were direct injuries. Mean absence after direct injuries was 11 days shorter than after indirect injuries.

\section{How might it impact on clinical practice in the near future?}

Our data will help team physicians distinguish different types of muscle injuries and provide more accurate estimates of return to play. These data can help to develop an algorithm for the management of muscle injuries. We respectfully suggest that the definition 'muscle injury' be updated to be 'an indirect or direct injury to the muscle leading to an athlete being unable to fully participate in training or match play/competition'.

Acknowledgements The authors wish to thank the participating clubs, medical staff and players. The statistical advice of Henrik Magnusson (MSc) is gratefully acknowledged.

Contributors PU designed this study, analysed the data and drafted and revised the paper, H-WM-W revised the paper. JE designed and monitored data collection, analysed the data and revised the paper. He is the guarantor.

Funding This study was supported by grants from UEFA.

Competing interests None.

Ethics approval The participating medical teams were informed about the study. The study design underwent an ethical review and was approved by the UEFA Football Development Division and the Medical Committee.

Provenance and peer review Not commissioned; externally peer reviewed.

\section{REFERENCES}

1 Mueller-Wohlfahrt HW, Haensel L, Mithoefer K, et al. Terminology and classification of muscle injuries in sport: the Munich consensus statement. Br J Sports Med 2013;47:342-50

2 Ekstrand J, Askling C, Magnusson $\mathrm{H}$, et al. Return to play after thigh muscle injury in elite football players: implementation and validation of the Munich muscle injury classification. Br J Sports Med 2013;47:769-74.

3 Askling CM, Malliaropoulos N, Karlsson J. High-speed running type or stretching-type of hamstring injuries makes a difference to treatment and prognosis. Br J Sports Med 2012:46:86-7.

4 Askling CM, Tengvar M, Saartok T, et al. Proximal hamstring strains of stretching type in different sports: injury situations, clinical and magnetic resonance imaging characteristics, and return to sport. Am J Sports Med 2008;36:1799-804.

5 Ekstrand J, Hagglund M, Walden M. Epidemiology of muscle injuries in professional football (soccer). Am J Sports Med 2011;39:1226-32.

6 Ekstrand J, Healy JC, Walden $\mathrm{M}$, et al. Hamstring muscle injuries in professional football: the correlation of MRI findings with return to play. Br J Sports Med 2012;46:112-17.

7 Kerkhoffs GM, van Es N, Wieldraaijer T, et al. Diagnosis and prognosis of acute hamstring injuries in athletes. Knee Surg Sports Traumatol Arthrosc 2013;21:500-9.

8 Rechel JA, Yard EE, Comstock RD. An epidemiologic comparison of high school sports injuries sustained in practice and competition. J Ath/ Train 2008:43:197-204.

9 Trojian TH. Muscle contusion (thigh). Clin Sports Med 2013;32:317-24.

10 Diaz JA, Fischer DA, Rettig AC, et al. Severe quadriceps muscle contusions in athletes. A report of three cases. Am J Sports Med 2003;31:289-93.

11 Hagglund M, Walden M, Bahr R, et al. Methods for epidemiological study of injuries to professional football players: developing the UEFA model. $\mathrm{Br}$ J Sports Med 2005;39:340-6.

12 Fuller CW, Ekstrand J, Junge A, et al. Consensus statement on injury definitions and data collection procedures in studies of football (soccer) injuries. Clin J Sport Med 2006;16:97-106

13 Jackson DW, Feagin JA. Quadriceps contusions in young athletes. Relation of severity of injury to treatment and prognosis. J Bone Joint Surg Am 1973;55:95-105

14 Jarvinen TA, Jarvinen TL, Kaariainen $M$, et al. Muscle injuries: biology and treatment. Am J Sports Med 2005;33:745-64.

15 Orchard J, Best TM. The management of muscle strain injuries: an early return versus the risk of recurrence. Clin J Sport Med 2002;12:3-5.

16 Junge A, Dvorak J, Rosch D, et al. Psychological and sport-specific characteristics of football players. Am J Sports Med 2000;28:S22-8.

17 Ekstrand J, Hagglund M, Walden M. Injury incidence and injury patterns in professional football: the UEFA injury study. Br J Sports Med 2011;45:553-8.

18 Ryynanen J, Junge A, Dvorak J, et al. Foul play is associated with injury incidence: an epidemiological study of three FIFA World Cups (2002-2010). Br J Sports Med 2013;47:986-91

19 Junge A, Dvorak J, Graf-Baumann T. Football injuries during the World Cup 2002. Am J Sports Med 2004;32:23S-7S.

20 Walden $M$, Hagglund $M$, Ekstrand J. UEFA Champions League study: a prospective study of injuries in professional football during the 2001-2002 season. $\mathrm{Br} J$ Sports Med 2005:39:542-6.

21 Noonan TJ, Garrett WE Jr. Muscle strain injury: diagnosis and treatment. J Am Acad Orthop Surg 1999;7:262-9.

22 Koulouris G, Connell DA, Brukner $P$, et al. Magnetic resonance imaging parameters for assessing risk of recurrent hamstring injuries in elite athletes. Am J Sports Med 2007;35:1500-6.

23 Megliola A, Eutropi F, Scorzelli A, et al. Ultrasound and magnetic resonance imaging in sports-related muscle injuries. Radiol Med 2006;111:836-45.

24 Schneider-Kolsky ME, Hoving JL, Warren P, et al. A comparison between clinical assessment and magnetic resonance imaging of acute hamstring injuries. Am J Sports Med 2006;34:1008-15.

25 Slavotinek JP. Muscle injury: the role of imaging in prognostic assignment and monitoring of muscle repair. Semin Musculoskelet Radiol 2010;14:194-200.

26 Boeck J, Mundinger $P$, Luttke $G$. Magnetic resonance imaging. In: Mueller-Wohlfahrt HW, Ueblacker P, Haensel L, Garrett WE, eds. Muscle injuries in sports. Stuttgart, Germany: Thieme, 2013:203-225.

27 Reurink G, Goudswaard GJ, Tol JL, et al. MRI observations at return to play of clinically recovered hamstring injuries. Br J Sports Med 2014;48:1370-6.

28 Sanfilippo JL, Silder A, Sherry MA, et al. Hamstring strength and morphology progression after return to sport from injury. Med Sci Sports Exerc 2013;45:448-54 